\title{
Moving on from scaling up: Further progress in developing social impact measurement in the third sector
}

\section{Colin Dey* \& Jane Gibbon}

Division of Accounting \& Finance, Stirling Management School, University of Stirling, UK, \& Newcastle University Business School, Newcastle-upon-Tyne, UK.

* Corresponding author. Email: colin.dey@stir.ac.uk.

THIS IS A PRE-PUBLICATION VERSION OF AN ACCEPTED MANUSCRIPT. THE PUBLISHED VERSION SHOULD BE CITED AS:

Dey, C., \& Gibbon, J. (2017). Moving on from Scaling Up: Further Progress in Developing Social Impact Measurement in the Third Sector. Social and Environmental Accountability Journal, Vol. 37, No. 1, pp. 66-72.

http://dx.doi.org/10.1080/0969160X.2017.1285712 


\title{
Moving on from scaling up: Further progress in developing social impact measurement in the third sector
}

\begin{abstract}
In 2011, we published an article in SEAJ (Gibbon \& Dey, 2011) that explored various issues surrounding the measurement of social impact in Third Sector Organisations (TSOs). In the little over five years since it was published, we have been surprised to discover that our article has emerged as one of SEAJ's most cited (and downloaded) publications. This prompted us to take a closer look at where our paper was being cited and obtain further insight as to why and how the paper has been used across a variety of fields, within both theoretical and empirical studies, by both academics and practitioners. Relevant to both researchers and practitioners, our review provides a useful snapshot that brings together a broad literature to explore how and where social impact measurement for social enterprise and values based organisations is developing.
\end{abstract}

Keywords: social enterprise, social impact measurement, third sector

\section{Introduction}

In 2011, we published an article in SEAJ (Gibbon \& Dey, 2011) that explored various issues surrounding the measurement of social impact in Third Sector Organisations (TSOs). We were particularly interested in highlighting what at that time was a relatively new approach, known as Social Return on Investment (SROI), and in examining the extent to which it differed from the rather more familiar technique of Social Accounting \& Audit (SAA). Our comparison drew particular attention to the much greater emphasis within SROI on quantitative and monetised measures such as the 'SROI ratio', which calculates a monetised 'return' on a notional $£ 1$ of investment. We argued that the apparent simplicity and clarity of such measures was misleading and potentially meaningless, since they depended upon the use of highly subjective proxies to measure the kind of 'soft' outcomes that are typical in a TSO context. However, against a backdrop of increasing demands for greater accountability in the delivery and funding of public services, we also acknowledged that SROI was likely to be attractive 
to policy-makers, fundraisers and investors, because of its promise to quantify social value creation and make comparative assessments of social value. Whilst expressing concern that the growth of SROI might be detrimental to both SAA and to TSOs, we concluded that a more worthwhile approach might be to incorporate quantitative measures such as SROI within a wider SAA framework, and that the theoretical and practical issues arising from this could be explored as a potentially fruitful avenue of further research.

In the little over five years since the article was published, we have been surprised to discover that Gibbon \& Dey (2011) has emerged as one of SEAJ's most cited (and downloaded) publications ${ }^{1}$. This, together with the ease of access to tools such as Google Scholar, prompted us to take a closer look at where our paper was being cited. It soon became apparent that the article has not only been of interest to others in the social accounting literature, but has also been cited in a number of wider subject fields with an interest in social impact measurement and TSOs. Given these initial observations, we decided it would be useful to obtain further insight as to why and how the paper has been used across these wider subject areas, by analysing in more detail all of the journal articles which have cited our paper. Our intention was not to measure the impact of the paper through detailed quantitative citation analysis, but in a more modest way to examine the content of all the citations to see how, why and where the paper has been used across a variety of fields, within both theoretical and empirical studies, by both academics and practitioners. We also examined past and current trends in citation patterns, to help understand the evolving nature of arguments around the limitations and critiques of the two particular methods of social impact measurement. The review provides a focused and detailed examination of recent empirical and theoretical developments across social accounting and social enterprise that could be useful to both researchers and practitioners.

${ }^{1}$ Gibbon and Dey (2011) ranks $2^{\text {nd }}$ in $S E A J$ for citations, and $2^{\text {nd }}$ for downloads (once review articles are excluded). Source: http://www.tandfonline.com/toc/reaj20/current, accessed 16 January 2017. 


\section{Method \& Findings}

To take in the widest range of possible sources as a starting point, we used Google Scholar's citation list ${ }^{2}$ of our article. As of January 2017, this produced a total of 53 citations. Of these, 23 were identified as being published in refereed academic journals, with the remainder a mix of unpublished work, duplicate/early versions of papers, or other non peer-reviewed work. We then categorised the 23 journal articles by broad subject and year of publication, as shown in Table 1:

\section{INSERT TABLE 1 HERE}

As we suggested in our introduction, an unexpected initial observation from our analysis is that only a minority of the citations, particularly since 2014, come from recognised accounting journals. Three articles come from a single issue of Qualitative Research in Accounting \& Management (Cordery \& Sinclair, 2013; Luke et al., 2013; Morgan, 2013). Of the remaining five, three appear in SEAJ (Jardine \& Whyte, 2013; Luke, 2015; Vik, 2016) with one each in Sustainability Accounting Management \& Policy Journal (Costa \& Pesci, 2016) and European Accounting Review (Hall \& Millo, 2016).

Of the remaining 15 articles, seven appear in journals dedicated to the voluntary/non-profit sector (Arvidson et al., 2013, 2014; Arvidson \& Lyon, 2014; Mook et al., 2015; Owen et al., 2015; Walk et al., 2015; Bretos \& Marcuello, 2016) while five come from a variety of journals in business and management (Rath \& Schuyt, 2014; Hall et al., 2015; Slater \& Aiken, 2015; Polonsky et al., 2016; Serrano-Cinca et al., 2016). Of these, it is worth noting that Hall et al. (2015) is perhaps incorrectly categorised, since it is explicitly focused on accounting aspects and even includes the word "accounting" in the title of the paper. The final three articles are published in journals with more distinct professional subject domains of public health (Leck et al., 2014; Raeburn et al, 2015) and the built environment (Watson \& Whitley, 2016).

Starting with the articles published in voluntary/non-profit journals, the comparatively higher number of citations from this subject category undoubtedly

\footnotetext{
${ }^{2}$ Source:

https://scholar.google.co.uk/scholar?oi=bibs\&hl=en\&cites=14487736609218371658\&as_sdt $=5$, accessed 16 January 2017 .
} 
reflects the importance of impact measurement to organisations across the third sector. Looking more closely at the seven papers, most are based on case studies of the implementation of SROI within TSOs, with an emphasis on obtaining further insights into the practical issues at stake and the challenges encountered. The work of Arvidson and others features prominently in this group of studies (Arvidson et al., 2013, 2014; Arvidson \& Lyon, 2014), beginning with a more literature-driven discussion of the key issues surrounding SROI, which establishes an agenda for future empirical research (Arvidson et al., 2013). The authors share the concern outlined in Gibbon \& Dey (2011) that metrics such as the SROI ratio can have dysfunctional consequences for the way impact is measured and understood, and they call for further research on indicators of social value and how costs and benefits are specified and calculated. They also call for greater understanding of the interaction between impact evaluation and the wider financial and political environment, particularly in the UK context of a reformed welfare system with new routes of funding for TSOs.

Taking up this call, Arvidson et al. (2014), Arvidson \& Lyon (2014), Mook et al. (2015) and Owen et al. (2015) examine a variety of issues arising from the use of SROI within TSOs via a number of case studies. Some of these studies tend to focus in particular on the problems associated with impact measurement, with Arvidson \& Lyon (2014) highlighting the tendency for impact measurement to become decoupled from organisational strategy in the face of external monitoring pressures, and Owen et al. (2015) emphasising the difficulties smaller TSOs face in determining reliable proxies for social value. Others seek to develop more constructive methodological insights that might address the limitations of quantitative approaches to social impact measurement. Both Arvidson et al. (2014) and Mook et al. (2015) emphasise the importance of recognising different stakeholders' interpretations of social value and argue that a more pluralistic and interpretive approach to impact measurement is needed. Walk et al. (2015)'s study is only loosely related to impact measurement and does not consider SROI or SAA. Finally, Bretos \& Marcuello (2016) briefly consider, on a more theoretical level, the merits of SAA (rather than SROI) to the development of cooperatives in a globalised context.

Moving now to a brief review of the citations which appeared in other business and management journals, we found a much more diverse range of work within this category, including a much wider range of views about the potential of impact 
measurement to articulate social value and satisfy demands from funders and other key stakeholders. Rath \& Schuyt (2014) suggest impact measurement might empower a new form of 'entrepreneurial philanthropy' that could attract new investors and create new markets for solving social problems. Polonsky et al. (2016) survey managers of TSOs in Australia and the United States to explore opportunities (as well as challenges) associated with a sector-wide approach to impact measurement. Serrano-Cinca et al. (2016) examine the use of social net present value techniques to facilitate a more social and environmentally informed approach to microfinance credit scoring.

Elsewhere amongst this group of articles, the development of impact measurement approaches such as SROI is theorised in more depth, and consequently provides greater insights into the more problematic aspects of implementation. Slater and Aiken (2015) adopt an explicitly social constructivist position to examine the role of impact measurement amongst TSOs in the area of community composting. Drawing on institutional theory, the authors argue that a fundamental difficulty for policymakers demanding standardised approaches to impact measurement is the partial state of institutionalisation within third sector fields. The paper cautions against an overemphasis on such approaches and argues that equal emphasis be given to narrative forms of disclosure that enable more discussion between stakeholders. Finally, Hall et al. (2015) also adopt a more explicitly interpretive theoretical framework, to explore the ways in which accounting for social value is influenced by managers understandings of what forms of knowledge are acceptable and what technical and material resources are available. The authors suggest that these factors may determine which stakeholder voices are included in forms of accounting for social value and how those voices are represented. The work of Hall et al. (2015) is, as we suggested earlier, perhaps better categorised as accounting, and it is to this group of eight articles that we now turn.

Of the eight articles we identified in the accounting literature, four appeared in 2013, including a case study by Jardine and Whyte. Although the article was published in $S E A J$, both authors are in fact specialists in social work, while the setting for this study is the prison service. The authors highlight a range of practical problems associated with experimentation with SROI as a form of impact measurement, but also see potential benefits in the development of more robust quantitative measures, alongside softer measures, as a means of challenging agencies involved in the criminal 
justice system to improve decision making and deliver better outcomes in the prison service.

The other three articles from 2013 appeared in a single special issue of Qualitative Research in Accounting \& Management devoted to performance measurement in the third sector. Cordery \& Sinclair's (2013) literature review is thorough and wide-ranging and explores a variety of issues surrounding performance measurement. Of more specific relevance to our work are the studies by Luke et al. (2013) and Morgan (2013). Both draw on empirical findings to argue that the potential problems associated with SROI demonstrate that impact reporting should concentrate on reporting less ambitious, but more meaningful and reliable data and metrics. For Luke et al. (2013), this involves greater focus on the documentation of impacts themselves as a first step, followed by a form of social accounting in which realised benefits and costs are measured and reported. While this falls short of providing the kind of measure of total value created promised by SROI, the authors argue this is both unreliable and unnecessary. Morgan (2013) is also concerned with developing alternative frameworks for disclosure, but his study concentrates on examining the merits of narrative reporting as a means for measuring the performance of TSOs.

Of the remaining four papers in this group, Luke (2015) develops the arguments of Luke et al. (2013) to construct a tentative outline of a so-called 'statement of social performance' that incorporates both financial (revenues and expense) and non-financial (inputs and resources) measures to succinctly capture the key elements underpinning social performance. The author argues this reporting framework aligns well to existing financial reporting frameworks whilst at the same time providing a relevant, comparable and reliable summary of the performance of TSOs. Vik (2016) examines the use of SROI within the microfinance sector and argues that despite a strong emphasis on sophisticated quantitative methods, the sector is struggling to demonstrate it can credibly measure social impact because of the influence of selection bias within measurement processes. Drawing on the work of Luke et al. (2013), the author concludes that the use of SROI may be better understood as a form of symbolic legitimation. Hall \& Millo (2016) attempt to explain the increasing popularity of SROI amongst government policy-makers, and suggest that this may be due to its intrinsic capturability and communicability as a form of accounting. These attributes mean that it becomes more attractive to governments as a way of explaining and rationalising policy 
choices. Finally, Costa \& Pesci (2016) re-examine the question of stakeholder involvement in third sector impact measurement and argue that this issue has been under-theorised, leading to forms of practice where too much emphasis is put on single, standardised measures of performance. To address this shortcoming, the authors propose a multiple-constituency framework that discourages opportunistic and manipulative use of specific metrics and instead involves stakeholders directly in the management and selection of performance measures.

Looking at the final group of three articles which are most distant from the accounting literature, they perhaps inevitably reflect their subject-specific fields by adopting a more explicit practitioner focus. Raeburn et al. (2015) are concerned more with social enterprise than impact measurement, and only briefly consider issues of finance and accountability, but both Leck et al. (2015) and Watson and Whitney (2016) do examine the use of impact measurement within subject specific case study settings. These studies introduce SROI as a potentially promising method of impact measurement that might be applicable in the respective fields of healthcare and the built environment. Both studies also present findings from experimentation with SROI that recognise the problems and challenges faced, but from a purely technical and practical perspective.

\section{Summary}

Our findings indicate that the majority of articles used the citation as a basis for supporting an argument for social impact or to develop a critique of the approaches with some developing theory. The many concerns we outlined in our 2011 paper surrounding the use of SROI as a form of impact measurement in TSOs have now been extensively documented in a variety of case study settings. Amongst these many empirical studies are studies with a more practitioner-oriented focus which were published in subjectspecific journals quite distant from the accounting literature. These papers are perhaps less critical about SROI but this is perhaps understandable given the practitioner focus. At the same time, we observed other studies, especially in business journals, in which SROI and other highly quantitative forms of impact measurement are viewed much more positively. A number of other papers, particularly within the accounting and nonprofit literatures, make a more substantial theoretical contribution or provided both theoretical and empirical elements. A particularly welcome theme, emerging in more 
recent papers, is the re-theorising and re-connecting of impact measurement and reporting to the kind of pluralist stakeholder thinking that has been central to social accounting (see, especially, Hall et al., 2015; Costa \& Pesci, 2016). Also emerging, but to a lesser extent, are alternative proposals for impact measurement which provide potential ways of overcoming the well-documented concerns with measures such as SROI (Luke, 2015; Costa and Pesci, 2016). Our review provides a useful snapshot that brings together a broad literature that demonstrates how and where social impact measurement for social enterprise and values based organisations is developing. Overall, we conclude that research on social impact measurement both within and beyond the accounting literature is progressing well, not only in seeking to draw more empirically-grounded insights from studies of implementation, but also in developing more constructive theoretical perspectives on the development of impact measurement.

\section{References}

Arvidson, M., \& Lyon, F. (2014). Social impact measurement and non-profit organisations: Compliance, resistance, and promotion. VOLUNTAS: International Journal of Voluntary and Nonprofit Organizations, 25(4), 869-886.

Arvidson, M., Lyon, F., McKay, S., \& Moro, D. (2013). Valuing the social? The nature and controversies of measuring social return on investment (SROI). Voluntary Sector Review, 4(1), 3-18.

Arvidson, M., Battye, F., \& Salisbury, D. (2014). The social return on investment in community befriending. International Journal of Public Sector Management, 27(3), 225-240.

Bretos, I., \& Marcuello, C. (2016). Revisiting Globalization Challenges and Opportunities in the Development of Cooperatives. Annals of Public and Cooperative Economics, forthcoming.

Cordery, C., \& Sinclair, R. Measuring performance in the third sector. Qualitative Research in Accounting \& Management 10.3/4 (2013): 196-212.

Costa, E., \& Pesci, C. (2016). Social impact measurement: why do stakeholders matter?. Sustainability Accounting, Management and Policy Journal, 7(1), 99124.

Gibbon, J., \& Dey, C. (2011). Developments in social impact measurement in the third sector: scaling up or dumbing down?. Social and Environmental Accountability Journal, 31(1), 63-72.

Jardine, C., \& Whyte, B. (2013). Valuing Desistence? A social return on investment case study of a throughcare project for short-term prisoners. Social and Environmental Accountability Journal, 33(1), 20-32.

Hall, M., Millo, Y., \& Barman, E. (2015). Who and What Really Counts? Stakeholder Prioritization and Accounting for Social Value. Journal of Management Studies, 52(7), 907-934. 
Hall, M., \& Millo, Y. (2016). Choosing an Accounting Method to Explain Public Policy: Social Return on Investment and UK Non-profit Sector Policy. European Accounting Review, forthcoming.

Leck, C., Upton, D., \& Evans, N. (2014). Social Return on Investment: Valuing health outcomes or promoting economic values? Journal of Health Psychology, 21(7), 1481-1490.

Luke, B., Barraket, J., \& Eversole, R. (2013). Measurement as legitimacy versus legitimacy of measures: Performance evaluation of social enterprise. Qualitative Research in Accounting \& Management, 10(3/4), 234-258.

Luke, B. (2015). Measuring and Reporting on Social Performance: From Numbers and Narratives to a Useful Reporting Framework for Social Enterprises. Social and Environmental Accountability Journal, 36(2), 103-123.

Mook, L., Maiorano, J., Ryan, S., Armstrong, A., \& Quarter, J. (2015). Turning Social Return on Investment on Its Head. Nonprofit Management and Leadership, 26(2), 229-246.

Morgan, G. (2013). Purposes, Activities and Beneficiaries: assessing the use of accounting narratives as indicators of third sector performance. Qualitative Research in Accounting \& Management, 10(3/4), 295-315.

Owen, F., Li, J., Whittingham, L., Hope, J., Bishop, C., Readhead, A., \& Mook, L. (2015). Social Return on Investment of an Innovative Employment Option for Persons with Developmental Disabilities. Nonprofit Management and Leadership, 26(2), 209-228.

Polonsky, M. J., Landreth Grau, S., \& McDonald, S. (2016). Perspectives on social impact measurement and non-profit organisations. Marketing Intelligence \& Planning, 34(1), 80-98.

Raeburn, T., Hungerford, C., Sayers, J., Escott, P., Lopez, V., \& Cleary, M. (2015). Leading a recovery-oriented social enterprise. Issues in mental health nursing, 36(5), 362-369.

Rath, J., \& Schuyt, T. (2014). Entrepreneurial Philanthropy: An Exploratory Review. The Journal of Wealth Management, 17(3), 35.

Serrano-Cinca, C., Gutiérrez-Nieto, B., \& Reyes, N. M. (2016). A social and environmental approach to microfinance credit scoring. Journal of Cleaner Production, 112(4), 3504-3513.

Slater, R., \& Aiken, M. (2015). Can't you count? Public service delivery and standardized measurement challenges-the case of community composting. Public Management Review, 17(8), 1085-1102.

Vik, P. (2016). What's so social about Social Return on Investment? A critique of quantitative social accounting approaches drawing on experiences of international microfinance. Social and Environmental Accountability Journal, forthcoming.

Walk, M., Greenspan, I., Crossley, H., \& Handy, F. (2015). Mind the Gap: Expectations and Experiences of Clients Utilizing Job-Training Services in a Social Enterprise. Annals of Public and Cooperative Economics, 86(2), 221-244.

Watson, K. J., \& Whitley, T. (2016). Applying Social Return on Investment (SROI) to the built environment. Building Research \& Information, forthcoming. 


\begin{tabular}{|c|c|c|c|c|c|}
\hline Category/Year & 2013 & 2014 & 2015 & 2016 & Total \\
\hline Accounting & $\begin{array}{l}\text { Cordery \& } \\
\text { Sinclair; } \\
\text { Luke et al.; } \\
\text { Morgan; } \\
\text { Jardine \& } \\
\text { Whyte }\end{array}$ & & Luke & $\begin{array}{l}\text { Vik; } \\
\text { Costa \& Pesci; } \\
\text { Hall \& Millo* }\end{array}$ & 8 \\
\hline $\begin{array}{l}\text { Voluntary/ } \\
\text { non-profit }\end{array}$ & $\begin{array}{l}\text { Arvidson et } \\
\text { al. }\end{array}$ & $\begin{array}{l}\text { Arvidson et } \\
\text { al; } \\
\text { Arvidson \& } \\
\text { Lyon }\end{array}$ & $\begin{array}{l}\text { Mook et } \\
\text { al.; } \\
\text { Owen et } \\
\text { al.; } \\
\text { Walk et al. }\end{array}$ & $\begin{array}{l}\text { Bretos \& } \\
\text { Marcuello* }\end{array}$ & 7 \\
\hline Business/Mgmt & & $\begin{array}{l}\text { Rath \& } \\
\text { Schuyt }\end{array}$ & $\begin{array}{l}\text { Hall et al.; } \\
\text { Slater \& } \\
\text { Aiken }\end{array}$ & $\begin{array}{l}\text { Polonsky et al; } \\
\text { Serrano-Cinca } \\
\text { et al. }\end{array}$ & 5 \\
\hline $\begin{array}{l}\text { Other } \\
\text { Professions }\end{array}$ & & Leck et al. & $\begin{array}{l}\text { Raeburn et } \\
\text { al }\end{array}$ & $\begin{array}{l}\text { Watson \& } \\
\text { Whitley* }\end{array}$ & 3 \\
\hline & 5 & 4 & 7 & 7 & 23 \\
\hline
\end{tabular}

Table 1. Timeline and frequency of reviewed citations (total Google Scholar citations were greater)

* At time of writing, these articles were published online in 2016, but are forthcoming for publication in 2017 